\title{
Exploring the safety of nanoparticles in Australian sunscreens
}

\author{
Thomas Faunce \\ College of Law and \\ College of Medicine, Biology and the Environment, \\ Australian National University, \\ Fellows Road, ACton, Canberra ACT 0200, Australia \\ E-mail: Thomas.Faunce@anu.edu.au
}

\begin{abstract}
Engineered nanoparticles are now well recognised to possess a range of apparently unique and as yet under-researched toxicities Safety concerns about such nanoparticles in cosmetics such as sunscreens are fuelled by consideration of factors such as their size, high mobility in the body and unusual reactivities. Yet, published research relied upon by safety regulators suggests there are no significant adverse health effects from nanoparticle sunscreen preparations [such as those containing nanoparticulate zinc oxide $(\mathrm{ZnO})$ and titanium dioxide $\left.\left(\mathrm{TiO}_{2}\right)\right]$ despite free radical formation in the presence of light. This is chiefly because of minimal dermal absorption of skinapplied nanoparticles below the dead and highly keratinised cells of the stratum corneum. Influential non-governmental organisations and a NSW parliamentary inquiry have expressed concern that this research has inadequately accounted for issues associated with chronic use of these sunscreens over hairy, damaged or aged skin or flexural creases. It may be time for Australian safety regulators to apply the precautionary principle in this context and increase labelling requirements about the use of nanoparticles in sunscreens.
\end{abstract}

Keywords: nanoscience; nanotechnology; nanoparticles; sunscreens; precautionary principle; regulation; nanotoxicology; Australia.

Reference to this paper should be made as follows: Faunce, T. (2010) 'Exploring the safety of nanoparticles in Australian sunscreens', Int. J. Biomedical Nanoscience and Nanotechnology, Vol. 1, No. 1, pp.87-94.

Biographical notes: Thomas Faunce is an Associate Professor jointly in the College of Law and the College of Medicine, Biology and the Environment at the Australian National University. His latest book is Nanotechnology and Global Public Health with Edward Elgar International.

\section{Risks of nanomaterials in modern sunscreen formulations}

Engineered nanoparticles (ENPs) are now well recognised to possess a range of partially-researched toxicities capable of causing problems for regulators (Faunce, 2008; Oberdorster et al., 2005). Concerns about the safety of ENPs in medicines and cosmetics are fuelled by consideration of factors such as the extremely small size, high mobility in the body and unusual reactivities (Borm et al., 2006; Nel et al., 2006). 
Australia has the highest rate of skin cancer in the world, and as such the use of sunscreens is a vital aspect of our skin protection strategy, despite claims that sunscreens may lack some of the effectiveness against ultraviolet light-induced free radicals originally claimed (Haywood et al., 2003). Of the 1,200 sunscreens authorised by the Australian Therapeutic Goods Administration (TGA) as of 2005 for supply in Australia, 228 contain zinc oxide $(\mathrm{ZnO}), 363$ contain titanium dioxide $\left(\mathrm{TiO}_{2}\right)$ and 73 contain both (TGA, 2006). Of these, $70 \%$ of $\mathrm{TiO}_{2}$-containing sunscreens and $30 \%$ of $\mathrm{ZnO}$-containing sunscreens sold in Australia use those substances in nanoparticulate form. $\mathrm{ZnO}$ and $\mathrm{TiO}_{2}$ are particularly valuable to sunscreen manufacturing because of their ability to filter UVA as well as UVB light, giving broader protection than other agents (TGA, 2006). Nanoscale $\mathrm{ZnO}$ is particularly efficient in the absorption of UV light in the UVA spectrum, whereas nanoscale $\mathrm{TiO}_{2}$ has higher scattering efficiency than $\mathrm{ZnO}$ and is most effective against UVB (Dussert et al., 1997).

From a consumer point of view, one disadvantage of macroscale $\mathrm{ZnO}$ and $\mathrm{TiO}_{2}$ is that they leave a white colour on the skin following sunscreen application. When used in nanoparticle form, $\mathrm{ZnO}$ and $\mathrm{TiO}_{2}$ can no longer be seen on the skin, but still retain their sun-screening properties (Maier and Korting, 2005). Proponents of nanoparticulate sunscreens argue that nanoparticulate ingredients in fact deflect or scatter UV light more efficiently than their macro counterparts (Nohymek et al., 2007). Other evidence suggests that sun-screening properties are neither enhanced nor decreased when the chemical is in nano form (NSW Govt., 2008).

The International Agency for Research on Cancer (IARC) and the US Toxicology Program both rate $\mathrm{TiO}_{2}$ as an improbable human carcinogen (NIOSH, 2005). Lung neoplasias do occur in rats exposed to inhaled $\mathrm{TiO}_{2}$, but this may be a species specific response (ASCC, 2006). Recent work, however, has shown that ultrafine $\mathrm{TiO}_{2}$ (10-20 nm) induced oxidative DNA damage, lipid peroxidation and micronuclei formation in a human bronchial epithelial cell line (Gurr et al., 2005).

When $\mathrm{TiO}_{2}$ particles are incorporated into cells, mobilisation of electrons by absorption of UVA light causes the generation of reactive oxygen species (ROS) with induction of DNA in human cells (strand breakage and base modification) and cell membrane damage. Thus $\mathrm{TiO}_{2}$ can be used to kill cancer cells by encouraging cell uptake and then irradiating with UVA with subsequent cytotoxicity (Hirakawa et al., 2004). In sunscreens and cosmetic preparations, $\mathrm{TiO}_{2}$ is generally coated to reduce this photocatalytic activity because ambient UVR is $>90 \%$ UVA (Maeir and Korting, 2005). Yet recently, a particular sunscreen product marketed in Australia (but as yet not publicly identified) containing the uncoated, anatase form of $\mathrm{TiO}_{2}$ has been shown to cause a damaging photocatalytic reaction on steel roofing (Barker and Branch, 2008).

Inorganic zinc salts are known to be potent biocides, and zinc oxide nanoparticles (as well as manufacturing by-products containing zinc) manufactured for use in cosmetics and sun-screens are thus currently subject to disposal restrictions in most nations (ASCC, 2006). The US Food and Drug Administration (FDA) states that it is aware of nanotechnology-related claims made for certain sunscreens and though 'currently not aware of any safety concerns is planning additional studies to examine the effects of select nanoparticles on skin penetration' (FDA, 2009). 


\section{Nanoparticulate penetration below the stratum corneum}

Given the above information on potential cytotoxicity, the key regulatory issue for the TGA in determining the safety of ENP-containing sunscreen preparations concerns dermal penetration. A considerable body of published research claims to demonstrate a lack of ENP penetration beyond the stratum corneum (Schulz et al., 2002; Pflucker et al., 2001). However, such studies have mostly been done in non-human skin (Garner et al., 2006) or on multiple sites in a single subject (Schulz et al., 2002) taking little, if any, account of demonstrated wide inter-individual variability (Vogt et al., 2006). Likewise, until recently, they appear not to have systematically considered cuts, abrasions, dermatological conditions, co-application of insect repellents, pre-existing UV damage, age or flexure of skin, despite the impact it is reasonable to expect these factors are likely to have on ENP sunscreen absorption in daily life. ENP size is clearly of the utmost importance.

A recent review of the literature, however, concluded that very small $(5-20 \mathrm{~nm}) \mathrm{TiO}_{2}$ ENPs do penetrate into the dermis and can interact with the immune system (Krielgaard, 2002). Vogt et al. (2006), examining ENPs to facilitate transcutaneous vaccination, have shown that, after cyanacrylate skin surface stripping (which removes $30 \%$ of the stratum corneum, including keratinised material, lipids and cell debris from the follicular openings), ENPs of $40 \mathrm{~nm}$ or less do penetrate the stratum corneum both via follicular ducts and in perifollicular tissue, to enter perifollicular Langerhans cells (potent antigen presenting cells).

\subsection{Intact skin}

A study by Ryman-Rasmussen et al. (2006) examined penetration of quantum dots into porcine skin flow through diffusion cells in conjunction with confocal microscopy. Quantum dots (QDs) are heterogeneous nanoparticles that consist of a colloidal cone surrounded by one or more surface particles. Unlike other ENPs, QDs are easily detected due to unusually intense and photostable fluorescence. They are commercially available in various sizes and shapes with different surface coatings. The study showed that dermal penetration of QDs through intact (no abrasion or mechanical stressors) epidermal layers and into the richly vascularised dermis could provide access for systemic absorption (Ryman-Rasmussen et al., 2006).

\subsection{Flexed skin}

In a study by Rouse et al. (2007) dermatomed porcine skin was fixed to a flexing device, topically dosed with ENPs and either flexed for 60 or 90 minutes, or left unflexed. Confocal microscopy depicted dermal penetration of nanoparticles at $8 \mathrm{~h}$ in skin flexed for 60 or 90 minutes, but $24 \mathrm{~h}$ in unflexed skin. The ability of nanoparticles to traverse through lipid lamellae and enter into the dermis of skin suggests nanoparticles could be absorbed by the capillaries of the papillary layer with the potential to localise elsewhere in the body (Rouse et al., 2007). 
The study by Rouse et al. (2007) confirms that mechanical stressors, such as those associated with a repetitive flexing motion, increase the rate at which particles traverse into the dermis. Its results cohere with those of Tinkle et al. (2003), who demonstrated in that topical application of beryllium ENPs (0.5-1 micron) in conjunction with skin flexion results in some dermal absorption.

\subsection{Abraded skin}

In 2008, Zhang and Montiero-Riviere studied QD penetration of flexed, taped and abraded rat skin. Abrasion was shown to allow QDs to penetrate deeper into the dermal layers. When different mechanical stressors were applied to rat skin dosed with QDs, no penetration of QDs was shown in the non-flexed control, flexed and tape-stripped skin, but minimal penetration was observed in abraded skin. Occasionally, retention of QDs in hair follicles was observed in abraded skin (Zhang and Montiero-Riviere, 2008).

Recent ENP sunscreen preparations contain stabilisers that overcome particle aggregation and ensure nanoparticle dispersion (Advanced Nanotechnology, 2008). It will be important to repeat such experiments using these new preparations in chronic use over a wide variety of skin types and locations.

\section{Current regulation of nano-sunscreens in Australia}

Under the Therapeutic Goods Act 1989 (Cth) ('the Act') the TGA is responsible for regulating therapeutic goods, including sunscreens, in Australia. In fulfilling their responsibilities, the TGA is required by s4 of the Act to ensure the 'quality, safety, efficacy and timely availability of therapeutic goods'. The Act further requires therapeutic goods to be entered on the Australian Register of Therapeutic Goods (ARTG) before they are supplied in Australia.

Sunscreen products with a sun protection factor of four or above, including $\mathrm{TiO}_{2}$ and $\mathrm{ZnO}$, are classified as 'low risk' or 'listed goods' for the purpose of being entered onto the ARTG. Under this framework, the ARTG does not differentiate listed ingredients such as $\mathrm{TiO}_{2}$ and $\mathrm{ZnO}$ on the basis of their size. In undertaking a human risk assessment of 'listed' sunscreen ingredients, the TGA is only required to assess the sunscreen in response to concerns about the product's safety in relation to human health, after the product has been entered into the ARTG.

Originally $\mathrm{TiO}_{2}$ and $\mathrm{ZnO}$ were ARTG listed because the quality and safety of these ingredients in molecular form had been established and no smaller forms were available. If ENPs used in sunscreens were investigated and found to have different properties from their bulk counterparts, separate safety assessment by the manufacturers would be required in accordance with TGA policy regarding new active chemical ingredients (TGA, 2003).

In their Safety of Sunscreens report the TGA adopted the position that sunscreen products containing ENPs do not require their own quality and safety assessment, because, ostensibly, "there is no evidence that sunscreens containing these materials pose any risk to the people using them" (TGA, 2006).

This Australian TGA position may be contrasted with the view of the European Commission's Scientific Committee on Consumer Products (SCCP), who at the request of the European Commission delivered an opinion in 2005 on the safety of nanomaterials 
in cosmetics products (SCCP, 2005). Under the terms of reference, the SCCP was, "requested to review, and if appropriate, to amend its notes of guidance for the testing of cosmetic ingredients and their safety evaluating as concern cosmetic ingredients in the form of nanomaterials" (SCCP, 2005). Pursuant to the Cosmetics Directive, a sunscreen product is considered to be a cosmetic product for the purposes of the European regulatory framework, and as such, came within the scope of the committee's opinion.

In their final opinion, released in December 2007, the SCCP concluded that, "there are large data gaps in risk assessment methodologies with respect to nanoparticles in cosmetic products" [SCCP, (2007), p.34]. In relation to the use of insoluble metal oxide nanoparticles in cosmetic products, such as $\mathrm{TiO}_{2}$ and $\mathrm{ZnO}$, the SCCP stated that while,
"[c]urrent investigations of nanoparticle penetration into the skin using static imaging technology are unable to detect small fractions of nanoparticles reaching the dermis, vascular bed of the dermis, and hence, the blood stream. However, if the dose of nanoparticles is very large, as is the case for $\mathrm{TiO}_{2}$ in sunscreens, even fractions as small as 10-4 may cause accumulation and subsequent inflammation in secondary target organs." [SCCP, (2007), p.34]

Based on this uncertainty, the SCCP concluded that,

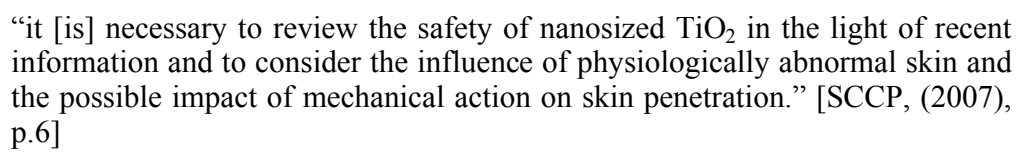

\section{Potential reform: the New South Wales parliamentary inquiry}

In a Final Report delivered in 2008, the New South Wales Government parliamentary inquiry appears to have responded to concerns, such as those of the European SCCP, by recognising the potential adverse health effects from the use of $\mathrm{TiO}_{2}$ and $\mathrm{ZnO}$ ENPs in sunscreen cosmetics.

The report recognised that the unique properties exhibited by many nanomaterials raised the question of whether the existing regulatory frameworks in Australia for the management of products incorporating chemicals are sufficient to cover the health, safety and environment concerns potentially posed by nanomaterials [NSW, (2008), p.xii]. During the parliamentary inquiry, the Committee found the most frequent concern expressed about the current regulatory frameworks was the fact that nano versions of existing chemicals are not automatically assessed as new chemicals [NSW, (2008), p.xii]. Recommendation 1 of the report addressed this concern, suggesting that "the New South Wales Government recommend that nano-versions of existing chemicals are assessed as new chemicals" [NSW, (2008), p.48]. This would have the effect of requiring manufacturers to provide a more detailed safety data set to regulators.

In relation to sunscreens, the report acknowledged consumer concerns regarding the absence of any labelling requirement for nanomaterials constituents. Though the Committee did not find it feasible to require all products manufactured via nanotechnology be labeled as such, they found a very strong case to require the labelling of sunscreens to indicate the presence of materials at the nanoscale [NSW, (2008), p.xv]. Recommendation 6 of the report thus reads: "That the New South Wales Government recommend that ingredient labeling requirements for sunscreens and cosmetics include the identification of nanoscale materials" [NSW, (2008), p.77]. The NSW Government is 
due to respond to this report and its recommendations in early 2009. In 2010, as a result of international harmonisation efforts in good manufacturing practice (GMP), Australian sunscreen manufacturers will have to comply with Annex 9 requirements of the Pharmaceutical Inspection Convention and Pharmaceutical Inspection Cooperation Scheme (jointly referred to as PIC/S). At present those standards do not create specific requirements for GMP in relation to use of nanoparticles in sunscreens.

\section{Conclusions}

Currently, no health technology regulator internationally specifies distinct safety regulations or requirements that must be met by manufacturers using ENPs in sunscreens or other health products. No government has yet established regulation to allow the public to make informed choices through proper labelling.

In a significant breakthrough for campaigners against the unregulated use of nanoparticulate sunscreens, the iconic Australian 'nano-sunscreen' brand Invisible Zinc, previously endorsed by model Megan Gale, has announced a change to their formulation which will render the sunscreen 'nano-free' (FOE, 2008). According to a survey by Friends of the Earth Australia, other admittedly nano-free brands include Banana Boat, the Cancer Council, Le Tan and The Wiggles (FOE, 2008). However, of the 68 sunscreen brands surveyed, nearly three quarters refused to disclose whether or not their formulations included nanomaterials, with only the Body Shop admitting to the use of nanoparticles in an aggregate form (FOE, 2009).

In a regulatory system which currently does not require sunscreen manufacturers to label whether listed ingredients present in their product are in nano form, it becomes increasingly difficult for patients, pharmacists and the general public to keep track of what is in the sunscreens they buy, and just how safe those sunscreens are. It will be an interesting challenge to the TGA if the NSW recommendations are adopted by the state government and then become uniform at the state level. No doubt federal regulators are looking at such developments closely.

There is clearly a need for further research on dermal absorption of sunscreen ENPs under a variety of realistic conditions, focusing on size and exposure limits. Currently, the CSIRO and Macquarie University are involved in such a program. Until its results are published, regulatory authorities should consider mandatory packaging warnings, expressing care about protracted use over cuts and abrasions, particularly on children. This would be an appropriate application of the precautionary principle (Faunce et al., 2008). Consideration could also be given to a requirement that sunscreen packaging clearly specify the average size or size range of ENPs in sunscreen formulations.

\section{Acknowledgements}

The author wishes to acknowledge research assistance provided by Ms. Megan Chalmers and Mr. Jimmy Bai. The author is the Project Director of an Australian Research Council Grant into safety and cost-effectiveness of nanomedicines. The ARC was not involved in the preparation of this paper. 


\section{References}

Advanced Nanotechnology (2008) 'ZinClear: the nanofine zinc oxide for cosmetic clarity and broad-spectrum UV protection', Advanced Nanotechnology Ltd., available at http://advancednanotechnology.com/pdfs/zinclear/ZinClear_brochure.pdf.

ASCC (2006) 'A review of the potential occupational health and safety implications of nanotechnology', Australian Safety and Compensation Council, available at http://www.ascc.gov.au/NR/rdonlyres/AC17BA49-8BA1-43B8-BC08-219DE53781E6/0/ ASCCReviewOHSImplicationsNanotechnology2006.

Barker, P.J. and Branch, A. (2008) 'The interaction of modern sunscreen formulations with surface coatings', Progess in Organic Coatings, Vol. 62, No. 3, pp.313-320.

Borm, P.J., Robbins, D., Haubold, S., Kuhlbusch, T. et al. (2006) 'The potential risks of nanomaterials: a review carried out for ECETOC', Part Fibre Toxicol, Vol. 3, p.11.

Dussert, A.S., Gooris, E. and Hemerle, J. (1997) 'Characterization of the mineral content of a physical sunscreen emulsion and its distribution onto human stratum corneum', International Journal of Cosmetic Science, Vol. 19, pp.119-129.

Faunce, T.A. (2008) 'Toxicological and public good considerations for the regulation of nanomaterial-containing medical products', Expert Opinion in Drug Safety, Vol. 7, No. 2, pp.103-106.

Faunce, T.A., Murray, K., Nasu, H. and Bowman, D. (2008) 'Sunscreen safety: the precautionary principle', The Australian Therapeutic Goods Administration and Nanoparticles in Sunscreens Nanoethics, Vol. 2, pp.231-240.

FDA (2009) 'Regulation of nanotechnology', United States Food and Drug Administration, available at http://www.fda.gov/nanotechnology/regulation.html.

Friends of the Earth (FOE) (2008) 'Top sunscreen brands pledge to avoid using high risk nano ingredients', Friends of the Earth Australia, available at http://www.foe.org.au/mediareleases/2008-media-releases/top-sunscreen-brands-pledge-to-avoid-using-high-risk-nanoingredients.

Friends of the Earth (FOE) (2009) 'Safe sunscreen guide', Friends of the Earth Australia, available at http://nano.foe.org.au/filestore $2 /$ download/299/FoEA\%20safe $\% 20$ sunscreen $\% 20$ consumer \%20guide\%202008-09\%20-\%20revised\%20web\%20version\%20Jan\%202009.pdf.

Gamer, A.O., Leibold, E. and van Ravenzwaay, B. (2006) 'The in vitro absorption of microfine zinc oxide and titanium dioxide through porcine skin', Toxicol In Vitro, Vol. 20, No. 3, pp.301-307.

Gurr, J.R., Wang, A.S., Chen, C.H. and Jan, K.Y. (2005) 'Ultrafine titanium dioxide particles in the absence of photoactivation can induce oxidative damage to human bronchial epithelial cells', Toxicology, Vol. 213, Nos. 1-2, pp.66-73.

Haywood, R., Wardman, P., Sanders, R. and Linge, C. (2003) 'Sunscreens inadequately protect against ultraviolet-A-induced free radicals in skin: implications for skin aging and melanoma?', Journal of Investigative Dermatology, Vol. 121, No. 4, pp.862-868.

Hirakawa, K., Mori, M., Yoshida, M., Oikawa, S. and Kawanishi, S. (2004) 'Photo-irradiated titanium dioxide catalyzes site specific DNA damage via generation of hydrogen peroxide', Free Radic Res, Vol. 38, No. 5, pp.439-447.

Kreilgaard, M. (2002) 'Influence of microemulsions on cutaneous drug delivery', Adv Drug Deliv Rev, Vol. 54, Suppl. 1, pp.S77-98.

Maier, T. and Korting, H.C. (2005) 'Sunscreens - which and what for?', Skin Pharmacol Physiol, Vol. 18, No. 6, pp.253-262.

Nel, A., Xia, T., Madler, L. and Li, N. (2006) 'Toxic potential of materials at the nanolevel', Science, Vol. 311, No. 5761, pp.622-627.

NIOSH (2005) 'Evaluation of health hazard and recommendations for occupational exposure to titanium dioxide', US NIOSH, CDC, available at http://www.cdc.gov/niosh/review/public/TIo2/pdfs/TIO2Draft.pdf. 
Nohymek, G.J., Lademann, J., Ribaud, C. and Roberts, M. (2007) 'Grey goo on the skin? Nanotechnology, cosmetic and sunscreen safety', Critical Reviews in Toxicology, Vol. 37, No. 3, p.251.

NSW Govt. (2008) 'Final report: nanotechnology in New South Wales', New South Wales Government.

Oberdorster, G., Oberdorster, E. and Oberdorster, J. (2005) 'Nanotoxicology: an emerging discipline evolving from studies of ultrafine particles', Environ Health Perspect, Vol. 113, No. 7, pp.823-839.

Pflucker, F., Wendel, V., Hohenberg, H., Gartner, E. et al. (2001) 'The human stratum corneum layer: an effective barrier against dermal uptake of different forms of topically applied micronised titanium dioxide', Skin Pharmacol Appl Skin Physiol, Vol. 14, Suppl. 1, pp.92-97.

Rouse, J.G., Yang, J., Ryman-Rasmussen, J.P., Barron, A.R. et al. (2007) 'Effects of mechanical flexion on the penetration of fulerene amino acid-derivatized peptide nanoparticles through skin', Nano Letters, Vol. 7, No. 1, pp.155-160.

Ryman-Rasmussen, J.P., Riviere, J.E. and Monteiro-Riviere, N.A. (2006) 'Penetration of intact skin by quantum dots with diverse physiochemical properties', Toxicological Science, Vol. 91, No. 1, pp.159-165.

Schulz, J., Hohenberg, H., Pflucker, F., Gartner, E. et al. (2002) 'Distribution of sunscreens on skin', Adv Drug Deliv Rev, Vol. 54, Suppl. 1, pp.S157-163.

Scientific Committee on Consumer Products (SCCP) (2005) 'Request for a scientific option: safety of nanomaterials in cosmetic products', Health and Consumer Protection Directorate-General, European Commission, available at http://ec.europa.eu/health/ph_risk/committees/04_sccp/docs/sccp_nano_en.pdf.

Scientific Committee on Consumer Products (SCCP) (2007) 'Opinion on safety of nanomaterials in cosmetic products', Scientific Committee on Consumer Products, Health and Consumer Protection Directorate-General, European Commission.

TGA (2003) 'Australian regulatory guidelines for OTC medicines', Therapeutic Goods Administration.

TGA (2006) 'Safety of sunscreens containing nanoparticles of zinc oxide or titanium dioxide', Therapeutic Goods Administration, available at http://www.tga.gov.au/npmeds/sunscreen-zotd.htm.

Tinkle, S.S., Antonini, J.M., Rich, B.A., Roberts, J.R. et al. (2003) 'Skin as a route of exposure and sensitization in chronic beryllium disease', Environ Health Perspect, Vol. 111, No. 9, pp.1202-1208.

Vogt, A., Combadiere, B., Hadam, S., Stieler, K.M. et al. (2006) ' $40 \mathrm{~nm}$, but not 750 or 1,500 nm, nanoparticles enter epidermal CD1a+ cells after transcutaneous application on human skin', J Invest Dermatol, Vol. 126, No. 6, pp.1316-1322.

Zhang, L.W. and Montiero-Riviere, N.A. (2008) 'Assessment of quantum dot penetration into intact, tape-stripped, abraded and flexed rate skin', Skin Pharmacology and Physiology, Vol. 21, pp.166-180. 